\title{
Sex 'n' drugs 'n' rock 'n' roll: the meaning and social consequences of pubertal timing
}

Andrea Waylen and Dieter Wolke

University of Bristol, Unit of Paediatric and Perinatal Epidemiology, Department of Community Based Medicine, 24 Tyndall Avenue, Bristol, UK

(Correspondence should be addressed to A Waylen; Email: andrea.waylen@bristol.ac.uk)

\begin{abstract}
This is a brief review of the normal changes in adolescent behaviour and the interplay between biology and social factors that occur at and around puberty, in an attempt to explain when this transition may become problematic The onset of puberty is a biological marker for an individual's transition from a non-reproductive to a reproductive state. Adolescence is a normal developmental transition associated with clearly visible physical changes, reorganization and pruning of neuronal circuits in the brain and the occurrence of new behaviours and interests. It is a time when new life tasks (orientation towards peers of the other sex, romantic and sexual involvement and mastering an educational career) need to be mastered. Parent-child conflict increases and becomes more intense as the adolescent struggles for more independence while still requiring support. These normal changes can become problematic if biological and social expectations diverge e.g. entering puberty very early or very late. While early pubertal onset in boys is likely to have beneficial effects, in girls precocious pubertal timing may have a negative impact on body-image, affect (or emotional well-being) and sex-role expectations. Other individual biological predispositions and genetic endowment may interact with social factors (e.g. peers, parenting style, neighbourhood) making adolescence either an adaptive or a challenging transition. There is a lack of sufficiently large longitudinal studies that have been able to study this interaction between genetics, biology and social environment on adolescent development. The Avon Longitudinal Study of Parents and Children (ALSPAC) cohort provides a unique opportunity to investigate the impact of pubertal timing on social behaviour. Planned assessments and concepts are outlined.
\end{abstract}

European Journal of Endocrinology 151 U151-U159

\section{Adolescence: a lifespan view}

During puberty an individual changes from a biologically non-reproductive, infertile child into an adult who can reproduce. This stage is one of the major changes in biology and incurs changes of similar magnitude in social expectations and responsibility in all societies around the world (1). It is a normative developmental phase which occurs between childhood and adulthood and is a stage experienced by nearly every human being. The majority of adolescents emerge unscathed from this transition to adulthood (a fact debated by many parents of teenagers undergoing this transitional process!). Many societies have special 'rites of passage' rituals intended to help the adolescent towards the world of adulthood and the new responsibilities therein (e.g. the Masai Mara send their youth out into the desert to look after their herds); however, in Western societies there is often a long gap between the time when an individual reaches physical maturity and the time when s/he has to take responsibility for her/his livelihood - Moffitt (2) has termed this 'the maturity gap'. Adolescence should be considered within a lifespan perspective. It is a phase during which abilities and life demands change to allow one to adapt to and acquire the skill sets necessary for adulthood.

This paper is concerned with describing the normative processes of adolescence, their associations with pubertal timing and a description of some of the adverse outcomes which may occur if pubertal timing goes awry.

Life task changes expected to occur within adolescence are a gradual transference from same sex to mixed sex peer groups, an increasing interest in and competition for romantic partners, negotiated changes within such romantic relationships and a transference of support and intimate knowledge sharing from parents to peers. In addition to these individual changes there are also changing educational and societal demands: individuals generally change schools just prior to or in early adolescence and are expected to become increasingly responsible for themselves and their academic performance; there is also a heightened 
social expectation to take civic responsibility and become a functioning member of the community. How well an adolescent copes with all of these different demands depends upon a range of factors in his/her family, peer group and wider neighbourhood as well as, in part, the teenager's own perception of this life stage. Adolescence can be considered as an opportunity to develop greater freedom and self-reliance or it can be considered as a threat.

The simplest approach by which to define adolescence is by chronological age (i.e. becoming a teenager at 13). Chronological age seems to be the most intuitive marker: as a child gets older, individuals and society anticipate evidence of changes in attitudes and behaviour indicating that the child is moving towards adulthood. A well-known, anecdotal experience in adolescence is being 'too old', 'too young' or 'old enough to know better' (depending on what it is they want to do). However, if one takes any group of teenagers born on the same day, it is unlikely that they would all be at the same stage with reference to attitudes, behaviour or pubertal status - growing up is concerned with more than just chronological age (3). The gap between chronological age and physical maturity differs enormously between individuals and between boys and girls in early adolescence, and this should be borne in mind when considering adolescence.

\section{Physical changes and maturity}

Physical changes associated with puberty are linked inextricably with hormonal influences: a chemical signal from the hypothalamus activates the pituitary gland to increase production of growth and gonadotrophic hormones. Growth hormones stimulate the growth of all body tissue and gonadotrophic hormones increase the production of oestrogen, progesterone and testosterone, facilitating reproductive maturity via the release of mature ova in females and the manufacture of sperm in males (4). The growth of body tissue results in a growth spurt which is easily observed: boys can grow by $23 \mathrm{~cm}$ in one year and girls by about $17 \mathrm{~cm}$; adolescents grow faster during puberty than they have at any time since infancy. Boys and girls also experience differentiated changes in shape: boys reduce their fat-to-muscle ratio and so gain a more lean appearance; girls increase the fat-to-muscle ratio and lay down fat deposits on the breasts and hips. As the sex organs mature, girls begin to release mature ova periodically and begin to menstruate while boys begin to manufacture sperm. The development of secondary sexual characteristics can also be observed: in boys the testes enlarge, the penis grows as do pubic, underarm and facial hair, they experience semenarche, the voice breaks and muscle development continues. In girls, breasts begin to develop and pubic and underarm hair grows. On average, girls complete the puberty growth spurt two years earlier than boys even though there is only about 6 months time difference between the onset of breast development in girls and an increase in testis volume in boys (the markers of puberty onset in each sex respectively).

These physical changes are well understood and are accepted as part of adolescence and the process of puberty: what is less well known is that other physiological changes occur within the brain during puberty $(5,6)$. There are changes in the frontal and temporal cortex, the amygdala and the hippocampus - these limbic areas (associated with emotion), particularly, are associated with increased volume during adolescence whereas cortical grey matter is pruned or reduced in volume. Frontal brain activity is enhanced during adolescence and this is assumed to contribute to advances in abstract thought and executive functioning such as planning behaviour/improved attentional capacities. Adolescence can be considered to be a sensitive developmental period with respect to the neural circuits involved in attitudes and behaviour, cognitive abilities and also mental health.

\section{The effects of puberty}

As the individual experiences these physical and cognitive changes s/he begins to experience changes in selfconcept (7) which vary according to context (i.e. whether in the presence of parents and family, peers or teachers etc.). Although self-concept and selfesteem start developing in early childhood, the adolescent is specifically concerned with the identity s/he wants to project (e.g. with regard to fashion, peer affiliation or attitudes). This process continues until the adult is well into his/her 40s! Part of this self-identification stage includes asking questions of oneself: 'who am I?', 'what do I want to do - is this what I should do?', 'what are my beliefs and values?' and 'who do I want to spend my time with?'. At the same time, the maturing adolescent is expected to synchronise his/her own beliefs with those of the important people around him/her: 'this is who you are', 'this is what you should do - and who you should do it with' and 'this is when you should do it'. This is one situation where discrepancies and challenges can arise: a difference in the stage that adolescents consider themselves at compared with the stage perceived by others (parents, teachers, society) may result in Moffitt's 'maturity gap' (2). The speed at which pubertal status changes can also determine whether the transition is smooth and uneventful or whether it is problematic: gradual changes which provide one with time to consider what is happening, make comparisons with one's peers and adapt are more likely to be uneventful whereas rapid changes which are asynchronous with one's peers and chronological age may be more troublesome. 


\section{What is normal and where does maladaptation start?}

Adolescence is a time when the majority of teenagers will experiment in various ways. As they get older, they may stay out late (after curfew), mix with 'forbidden peers', wear prohibited clothes and eventually move on to being pierced or tattooed, trying out 'soft' drugs (alcohol or tobacco) or becoming involved with more intimate relationship behaviours such as petting etc.

In order to review this experimental stage we will consider empirical evidence of what is normal (experienced by many adolescents) and what may be considered maladaptive with reference to romantic and sexual behaviour, drug use, mental health and antisocial behaviour. We will review factors that contribute to maladaptive behaviours and briefly consider general developmental principles that may explain why some behaviours become maladaptive in adolescence.

\section{Normative development: romance}

The development of romantic relationships is a major task for adolescents and one which occupies a large amount of time and effort. Although the development of romantic attachments and sexual behaviour may concur, it is not necessarily the case: sexual relationships may occur without any romantic attachment. Seiffge-Krenke (8) has developed a four stage model of adaptive stages in adolescent romantic development (ages are provided as a guide only). The initiation phase occurs at around 11 to 13 years: individuals re-acquaint with opposite sex peers having previously shown a preference for same sex social groups. Relationships are short, casual, less close and less intimate. At this stage, the individual's focus is on him/ herself: 'will others like me?, 'am I attractive enough?'.

The second stage is a status phase and occurs around the age of 14 to 16 years. Now the focus is on the right kind of relationship and peer acceptance of such relationships: "is my boy/girlfriend acceptable to my peers?'. This is a mid-position phase where the aim is to meet and interact with different partners - the existence of a partner at all is as important as anything else.

A focus on the romantic relationship itself does not occur until stage 3 - the affection phase - which occurs from about 17 to 20 years of age. This is the stage where the relationship becomes more caring and committed and is also likely to become more intimate. Here the concern is with being a good partner, making the other person feel happy and secure.

The final adult-like stage occurs from about 21 years of age in the bonding phase: relationships tend to be long-term, exclusive and committed - by this time most emotional support comes from the romantic partner. However, these relationships are also more pragmatic and negotiable: as well as wanting to please one's partner there is also a concern that one's own needs are fulfilled. It should be noted that, as with other developmental processes across adolescence, individuals progress through these stages at various rates.

While support is most likely to come from romantic partners as one progresses through adolescence, parents and peers may maintain a supportive role and these social relationships can themselves influence the quality of a romantic relationship (9). The cohesiveness of the family relationship, together with the level of communication and the flexible but authoritative control exhibited by parents throughout adolescence is important but begins to wane as peer and romantic relationships take precedence. If the relationships within the family are insecurely attached (less warm, open and supportive; more conflicting) it may be the case that adolescents look to their peers earlier and to an even greater extent than they do normally for emotional support (10).

When might romantic development be considered to be maladaptive? Wellings et al. (11) suggest that incompetent romantic or sexual behaviour (coerced or regretted, drug-induced or without adequate contraception) is potentially maladaptive. A study of Scottish teenagers (12) reported that one out of five boys and one out of seven girls were aged 14 or under when they first had sexual intercourse and of these only $60 \%$ reported that they had used contraception; $50 \%$ of the sexually active teenagers reported that they had been drinking alcohol before they had their first sexual encounter and within this group, only 13\% had used contraception (13). In addition to the very real risk of pregnancy, there is also a risk that the adolescent will contract a sexual infection. Between 1998 and 1999, cases of gonorrhoea rose by almost $40 \%$ in boys and about $25 \%$ in girls. There is also evidence that the oral transmission of sexual infection is increasing $(14,15)$; adolescents often consider that oral sex is not sex - pregnancy is not a consequence and contraception is therefore unnecessary. (It is not only adolescents who consider that oral sex is not really sex. After the Clinton affair, data from the USA were published indicating that $59 \%$ of Americans do not consider oral stimulation as $\operatorname{sex}(16)$.)

\section{Normative development: drugs}

\section{Legally available drugs: cigarettes and alcohol}

The Dunedin study (2) is a longitudinal investigation of just under 1000 children from birth into adulthood in New Zealand. Figure 1 shows the prevalence of behaviours such as smoking, being drunk in a public place or using marijuana across adolescence.

By the age of 21 , almost $90 \%$ of males and females had been involved in substance use of some kind, suggesting that this type of drug use may be normative 


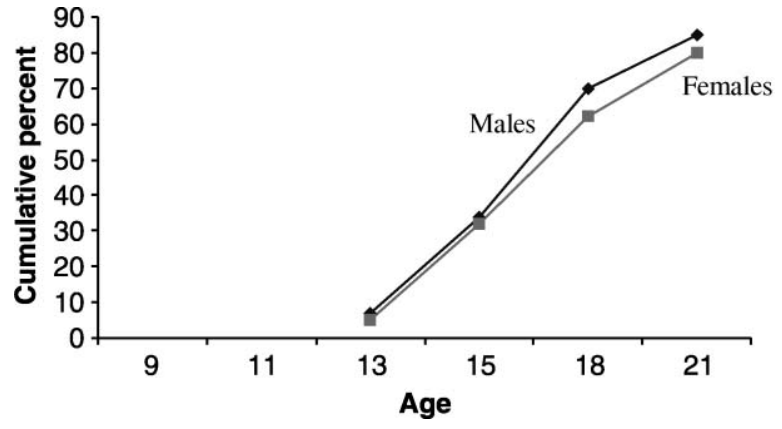

Figure 1 The onset of 'soft' drug use across adolescence in the Dunedin study.

behaviour in adolescence. Contrary to popular belief, no sex differences have been found in either the onset or the prevalence of substance use (17) - drug use is the only anti-social behaviour where girls are involved to the same extent as boys.

In the UK, at 12 years of age, $10 \%$ of adolescents report that they have smoked a cigarette in the last week - by 16 years of age, the proportion has increased to $25 \%$. Adolescents subjectively perceive benefits from smoking: they believe that it confers adult-like status and makes them appear to be sociable or tough; they report that smoking helps control both weight and stress and increases alertness and attention (18). It is also the case that adolescents believe that there are no health risks in the first few years of smoking (19). In certain groups, smoking seems to be taken up or maintained for specific reasons: $70 \%$ of eating-disorder females said they smoked as an alternative to eating, $66 \%$ because it relaxed them, while $47 \%$ smoked because they liked it; only 13\% smoked 'because their friends do' (20). Thus factors associated with individual differences may be involved when individuals smoke.

In most Western countries, between 80 and $90 \%$ of the population have consumed alcohol of some sort by the time they are 18 years of age (21). Sixty-two percent of UK teenagers aged 15 or less report having been drunk: of these $47 \%$ reported that they had drunk alcohol during the previous week (22). In the UK in 2003, over $330011-15$ year olds required hospital care as a result of drinking alcohol (23). Experimentation with alcohol may start even before adolescence. Within the Avon Longitudinal Study of Parents and Children (ALSPAC; www.alspac.bris.ac.uk), children had started to experiment with alcohol and tobacco by the time they were 8 years of age: $5 \%$ of the cohort report that they have drunk alcohol without their parents' permission and about 3\% report that they have tried a cigarette.

\section{Illegal drugs}

Young adolescents seem to be equally exposed to illicit drugs. A study in the UK reported that more than
$30 \%$ of 10 to 12 year olds had been exposed to illicit drugs and $3.9 \%$ had used them (24). In Western society, the substances most frowned upon for recreational use are illicit drugs. The stereotypical view is that drug users become involved in criminal activities in order to fund their drug habits; however, research has shown that this belief is probably inaccurate most criminal drug users report that they were involved in anti-social behaviours (theft etc.) before they started using drugs (17). It is also important to note that alcohol is the substance directly associated with disinhibition and, as a result, with disorderly and potentially dangerous conduct (e.g. driving or joy-riding offences). Consequently, as alcohol is the drug used most frequently by adolescents, it is a more important riskfactor for anti-social behaviour than all other illicit drugs taken together.

\section{Mental health in adolescence}

Drug use (whether tobacco, alcohol or illicit drugs) is sometimes considered to be an alternative method of self-medication when coping with stress and mental ill-health. Throughout childhood mental health and behavioural problems occur more often in males than in females e.g. learning difficulties, attention deficit hyperactive disorder (ADHD), behavioural disorders (25). However, at puberty, for the first time, girls display more morbidity than boys, with particular regard to affective disorders (anxiety and depression), eating disorders, smoking, teenage pregnancy etc. (26-28). Reasons for the sex difference in depression, which continues until after the menopause, include hormonal changes, female ruminative response style and negative cognitive style (i.e. attributing failure to themselves) and an increased tendency to perceive stressful events as depressogenic (29). Each of these may be linked either to the hormonal changes which occur during adolescence or alternatively to the physiological changes which occur in brain physiology during the same stage (29).

\section{Normative development: rock 'n' roll}

There are considerable changes in the relationship between parents and their growing teenagers. It is quite normal for adolescents to be involved in disputes at home (oppositional behaviour). Growing up means gaining increased autonomy from parents and increased independence.

During this process, parent-child relationships should become increasingly symmetrical as the powersharing process is renegotiated (7). If these changes are acknowledged and negotiated gradually the likelihood is that they will cause few long-lasting difficulties; however if they are acute and controversial the outcome may be different. Normative family development is accepted to include an increase in conflict throughout 
adolescence. In early adolescence it is normal for the frequency of parent-child conflict to increase as relationships begin to change whereas the intensity of such conflict increases as adolescents get older. Parents seem to take on definite roles: fathers are viewed more as sources of authority whereas mothers are more often looked to as a source of personal advice $(7,30)$. An authoritative parenting style (firm, affectionate and flexible) is likely to be adopted by parents who communicate well with their children - they know more about the child's peers and activities and are happy to adjust to a more symmetrical relationship when it is appropriate compared with those with an authoritarian or laissezfaire style (31). As parent-child relationships change, peers become a more regular source of support and values (7) and they facilitate an alternative source for modelling behaviour (32). As a result, peer norms (actual or perceived) are an important factor in many aspects of adolescent behaviour: peer groups may be determined by one's residential neighbourhood or school or by the activities a child is involved in or the effectiveness of parental monitoring.

The impact of the peer group can be supportive of positive aims or make antisocial behaviour more likely. Strong associations between an individual's peer group and involvement in anti-social or delinquent behaviour (33) have been found. This association is likely to be bidirectional: anti-social behaviour may increase if an adolescent mixes with delinquent peers and decrease if they mix with a different peer group (e.g. after changing neighbourhood/moving schools (34)). It is also the case that delinquent individuals are more likely to seek out like-minded peers so creating their own 'antisocial' support group (35).

At the onset of puberty, rates of anti-social behaviour increase rapidly, peak in mid-adolescence and then decline after 20 years of age as individuals settle into employment, longer term relationships etc. While there is no sex difference in drug use, boys are more often involved in (potentially illegal) anti-social behaviour. Up to $80 \%$ of males are estimated to have experienced police contact for minor infringement (36) while only $7 \%$ of 18-year-old boys deny any delinquent activity (2). In others words, at some level, a certain involvement in anti-social behaviour is normative, particularly for males. There are various categories of antisocial behaviour which (apart from overt aggressive behaviours - bullying/cruelty to people and animals) seem to be increasing across time. They include criminal behaviours e.g. theft, joy-riding, carrying weapons and drug abuse; school oppositional behaviours e.g. conflicts with teachers and suspension from school; covert anti-social behaviours e.g. truancy, graffiti; and status acts e.g. smoking, being drunk and watching 18 -rated films $(37)$. It has been suggested $(2,38)$ that many of these behaviours are undertaken in an attempt to seek adult status and bridge the maturity gap. However, anti-social tendencies are also associated with individual characteristics: behavioural predisposition, personality, self-esteem and IQ and also social factors e.g. peer group relationships, parental monitoring and school context. A minority of young children are involved in behaviours of this sort before they reach adolescence: the ALSPAC data for anti-social behaviour in children of 8 years of age is illustrated in Figs 2 and 3.

\section{Models for explaining persistent problem behaviour beyond adolescence}

Experimentation in adolescence is normative behaviour. However, if such experimentation becomes habitual and persistent it is more likely to become problematic as the adolescent moves towards adulthood. Maladaptive development and problematic behaviour sometimes involve an interaction between biology and environment.

\section{Pubertal timing}

There is speculation in the psychological literature that if there is asynchrony between an individual's physical developmental stage and social perceptions

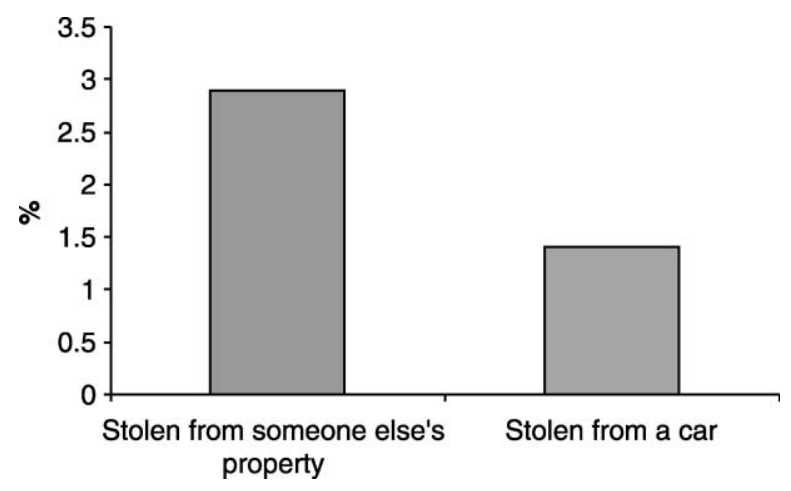

Figure 2 Percentage of the ALSPAC cohort admitting to theft behaviours at 8 years of age.

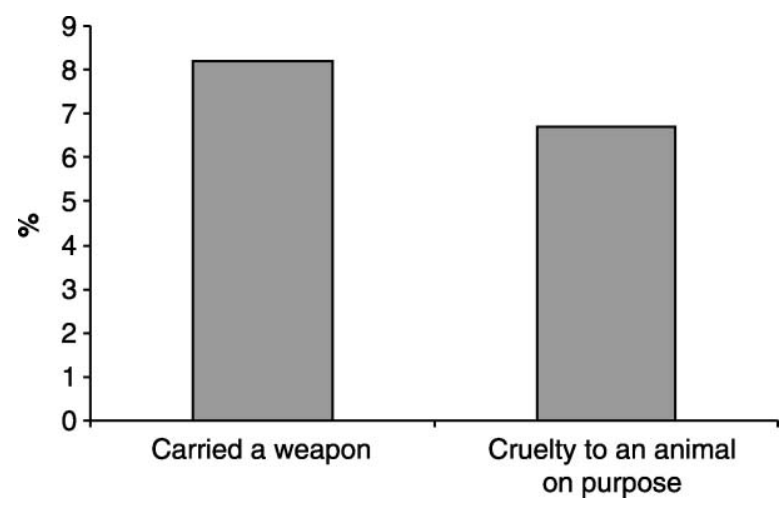

Figure 3 Percentage of the ALSPAC cohort admitting to aggressive behaviours at 8 years of age. 
of maturity (e.g. chronological age), there is an increase in the associated likelihood that development could become maladaptive $(17,39)$. Adolescents who mature 'off-time' may consider themselves to be different from their peers and so take on different behaviours and a different developmental profile. This hypothesis can be tested with an investigation of the behavioural adaptation of both males and females whose pubertal onset is either very early or very late (compared with age-related peers) $(7,39,40)$. As shown in Table 1 , previous research suggests that the effects of precocious or late pubertal timing may differ according to sex.

Early pubertal timing in females has been associated with proportionately more emotional problems, increased delinquency/anti-social behaviour as well as earlier drop-out from the schooling system and earlier parenthood. In part, this is likely to be a function of mixing with older, non-conventional peers (1). Early maturing girls look older than their years, are attractive to older boys as potential romantic or sexual partners, and can get into bars (and are increasingly exposed to drugs including alcohol and tobacco) or adult movies long before they are legally old enough. However, it seems that adverse effects are more likely to be a consequence if parental monitoring is ineffective, where familial standards and rules are unclear and where there is little focus on education. In contrast, early pubertal timing in boys seems to have mainly positive effects: they report increased self-esteem and high status within the peer group. These boys are often bigger and stronger than their same aged peers and so appear to be older. However, those boys who experience late pubertal onset seem to be those who are more likely to get into trouble - they are more involved in status seeking anti-social behaviours (i.e. trying to show off how 'cool' they are by getting involved in risky or law breaking behaviours) (see Stattin and Magnusson, 1990 for a review (1)).

\section{Biological predispositions}

When considering adolescent experimentation with substance use and other anti-social behaviours, it is important to note that individual variations in biological factors may interact with social and environmental factors resulting in adverse outcomes. Different models of alcohol abuse exist, all of which assume some biological predisposition. This disposition may be the amount of alcohol required to achieve the desired effect (Level of Response model (41)) or inherent temperamental characteristics (difficult/aggressive temperament and externalising anti-social behaviour) which impact on parenting and supervision (42) or, alternatively, a genetic tendency towards affective disorders (depression/anxiety) where alcohol is used in an attempt to self-medicate (43). In each of these models, as individuals begin to experiment with alcohol, a tendency to socialise with peers who drink a lot increases the likelihood that heavy drinking will become the norm.

\section{Social factors}

While biological factors can explain some of the variance in adolescents' anti-social behaviour, they are not sufficient. Across time, in some countries, differential rates of anti-social behaviour can be measured. Figure 4 shows rates across time for UK data: it can be seen that in the UK rates of anti-social behaviour have increased during the last 30 years (44). However, over the same period, rates of delinquent behaviour have been stable in Holland and have been falling in the United States. Biological characteristics such as pubertal timing cannot be used to explain either of these temporal or cultural differences: human biology has not changed in the last 30 years nor does it differ culturally to such an extent (in Western society at least). Rather, it seems that there are social factors which are most likely

Table 1 Differential effects of pubertal timing in boys and girls.

\begin{tabular}{llll}
\hline & & \multicolumn{1}{c}{ Girls } & \multicolumn{1}{c}{ Boys } \\
\hline Early maturation & Increases in: & Popularity & Self-image \\
& & Emotional problems & Achievement \\
& Parental conflict & Delinquency?? \\
& Delinquency & Anti-social behaviour?? \\
& Anti-social behaviour & Age of peer group \\
& Age of peer group & \\
& School drop-out & \\
& & Teenage pregenancy & \\
& Decreases in: & Self-image & \\
& School achievement & Feeling of inadequacy \\
& Increases in: & & Self-esteem \\
& Decreases in: & & Expectations \\
& & & Achievement \\
\hline
\end{tabular}

??, indicate that there is still a debate in the literature as to whether these are consequences of early maturation in boys. 


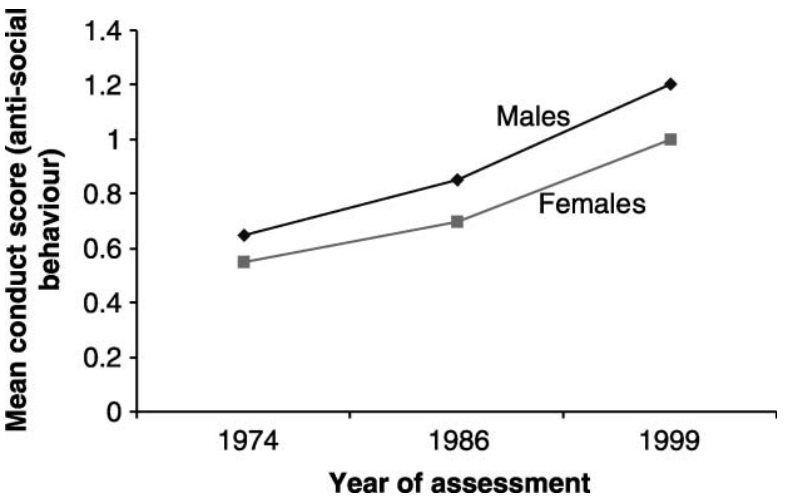

Figure 4 Temporal changes in anti-social behaviour in the UK (reproduced with permission from Collishaw et al. (44)).

responsible for such differences via either their own main effects or their interactions with biological factors; some of these have been alluded to throughout this paper and are summarised in Table 2.

\section{Early onset}

A most potent predictor of long term problematic behaviour is its time of onset (particularly if in childhood, i.e. before puberty). General anti-social behaviour, substance use and mental health problems are more likely to be maintained beyond the adolescent years if they were started in childhood (2). Those who start to smoke or drink or use other types of drugs pre-puberty are more likely to be those who will develop longterm deleterious substance use disorders. However, if the onset of tobacco or alcohol use is in mid-adolescence (after about 14 years of age), it is more likely that the behaviour will be both moderate and transitory. With particular regard to tobacco use, there are two other groups to consider: an experimenter group who try smoking in adolescence but who never take it up habitually, and a quitter group who try out smoking and stop $(18,45)$. Of course, there are also abstainers who never get involved in any behaviours of this sort. Non-normative behaviours which have their onset in adolescence, are occasional and occur within the peer group as a whole (e.g. drug taking, delinquency etc) are more likely to be transitory. This is especially likely if the parents are aware of the peers that their teenager mixes with, where there are firm but fair family rules and where the parent-child relationship is warm and open allowing for good communication and opportunities to confide (46).

\section{Need for further study}

While progress has been made towards a better understanding of some of the family, peer and neighbourhood influences on adolescent behaviour (mainly, it should be said, via cross-sectional research), there is a lack of research (in sufficiently large samples) into the early precursors of adolescent behaviour, interactions with genetic and biological factors, the mediating potential of social factors and the testing of alternative theories (e.g. on alcohol use) in one population. The ALSPAC study provides a unique opportunity of such longitudinal and interdisciplinary testing of alternative models.

\section{The ALSPAC study}

The ALSPAC study (47) has collected prospective data about child, mother and mother's partner either annually or twice yearly since pregnancy (the cohort is now in its 13 th year). These data include repeated measures of physical, medical and psychological information. The study has data on attachment, parental attitudes and behaviour regarding discipline; measures of parental anti-social behaviour and child anti-social behaviour collected from 8 years onwards (48). From ten years of age, we ask not only about the child's own anti-social behaviour but also about interpersonal anti-social behaviour between peers (49). We have clinical measures of mental health and pubertal stage data from the age of eight. At 11 years we start to collect data about peer relationships as they change from being platonic to becoming more romantic and eventually sexual (50). Detailed information is recorded about peer networks (51), school life (from teachers and parents reports) and we have biological samples for mother and child. A genetics laboratory which produces cell lines from parent and child DNA means that the study can collaborate on projects examining cross generational studies of gene-environment interactions (see Pembrey (52)). Currently, about 8000 children attend the clinic sessions and about 10000 return questionnaires regularly. The ALSPAC study has both

Table 2 Correlates of adolescent adjustment: reported associations between social factors of influence and delinquent behaviour.

\begin{tabular}{lccccc}
\hline & Sexual activity & Tobacco & Alcohol & Illicit drugs & Depression \\
\hline Individual & & & & & \\
Sex & Anti-social & & \\
Paberty & Peers & & & & \\
School & & & & & \\
\hline
\end{tabular}


the data and the power to examine exactly what happens during the adolescent transition: important changes in life tasks and their associations with both physiological and systems changes. The correlates and predictors of experimental, risk-taking and problem behaviour can be determined. Information about collaborations in this endeavour can be found at www.alspac.bris.ac.uk.

\section{Conclusion}

The aim of this paper was to discuss the impact of pubertal timing on adolescent social outcomes. Rather than follow a pathological perspective, our aim was to highlight adolescence as a normative process survived by the majority. It is a phase that involves a shifting of life tasks, a realignment of relationships and the acquisition of skills to adapt to and meet the responsibilities of an adult role. Admittedly, there are pathological outcomes to adolescent behaviour but these are associated with many factors, including pubertal timing, which make a contribution to outcomes for some adolescents. Moffitt's maturity gap (2) considers the interaction between both biological and social factors and the consequences of asynchrony between the two. Adolescence, in and of itself, is not a period of storm and stress (although it may appear to be to some parents); rather it is a normative process which may go awry as a result of interactions with other factors - if it is adapted to appropriately, long term adverse consequences are unlikely.

\section{References}

1 Stattin H \& Magnusson D. Pubertal Maturation in Female Development. Hillsdale, New Jersey: Lawrence Erlbaum Associates, 1990.

2 Moffitt TE. Adolescence-limited and life-course-persistent antisocial behavior - a developmental taxonomy. Psychological Review 1993100 674-701.

3 Weiss B \& Garber J. Developmental differences in the phenomenology of depression. Development and Psychopathology 200315 403-430.

4 Katchadourian $H$. The Biology of Adolescence. New York: WH Freeman, 1977.

5 Spear L. Neurobehavioural changes in adolescence. Current Directions in Psychological Science 20009 111-114.

6 Walker E. Adolescent neurodevelopment and psychopathology. Current Directions in Psychological Science $20021124-28$.

7 Steinberg L \& Morris AS. Adolescent development. Annual Review of Psychology 200152 83-110.

8 Seiffge-Krenke I. Testing theories of romantic development from adolescence to young adulthood - evidence of a developmental sequence. International Journal of Behavioural Development 2003 27 519-531.

9 Hazan C, Cadoret R \& Zeifman D. Sex and the psychological tether. In Advances in Personal Relationships - Attachment Processes in Adulthood, pp 151-178. Ed. Bartholomew. London: Jessica Kingsley, 1994.

10 Grant K, Grace P, Trujillo J, Halpert J, Kessler-Cordeiro A, Razzino B \& Davis T. Predicting desire for a child among lowincome urban adolescent girls - interpersonal processes in the context of poverty. Journal of Primary Prevention 200222 341-359.

11 Wellings K, Nanchahal K, Macdowall W, McManus S, Erens B, Mercer C, Johnson A, Copas AJ, Korovessis C, Fenton KA \& Field J. Sexual behaviour in Britain - early heterosexual experience. Lancet $20013581843-1850$.

12 Wight D, Henderson M, Raab G, Abraham C, Buston K, Scott S \& Hart G. Extent of regretted sexual intercourse among young teenagers in Scotland - a cross-sectional survey. British Medical Journal $20003201243-1245$.

13 Hooke A, Capewell S \& Whyte M. Gender differences in Ayrshire teenagers' attitudes to sexual relationships, responsibility and unintended pregnancies. Journal of Adolescence 200023 477-486.

14 Lewin T. Teenagers alter sexual practices, thinking risks will be avoided. The New York Times 1997 April 5th, 1997 p. 8.

15 Remez L. Oral sex among adolescents. Is it sex or is it abstinence? Family Planning Perspectives 200032 298-304.

16 Sanders SA \& Machover Reinisch J. Would you say you 'had sex' if...? Journal of the American Medical Association 1999281 275-277.

17 Moffitt T, Caspi A, Rutter M \& Silva P. Sex Differences in Anti-social Behaviour. 1st ed. Cambridge: Cambridge University Press, 2001.

18 Baker T, Brandon T \& Chassin L. Motivational influences on cigarette smoking. Annual Review of Psychology 200455 463-491.

19 Slovic P. What does it mean to know a cumulative risk? Adolescents' perceptions of short-term and long-term consequences of smoking. Journal of Behavioural Decision Making 200013 259-266.

20 Crisp A, Sedgwick P, Halek C, Joughin N \& Humphrey H. Why may teenage girls persist in smoking? Journal of Adolescence $199922657-672$.

21 Foxcroft D, Lowe G \& Lister-Sharp D. Teenage drinking - a 4 year comparative study. Alcoholism - Clinical and Experimental Research 1995 Alcohol 30 713-719.

22 Drink and Drug Poll Shows Teen Problem. BBC News UK edition, 2003.

23 Drink Binges Put Children in Hospital. BBC News UK edition, 2004.

24 UK Children Top Drugs League. BBC News UK edition, 1999.

25 Criss M, Pettit G, Bates J, Dodge K \& Lapp A. Family adversity, positive peer relationships and children's externalising behaviour - a longitudinal perspective on risk and resilience. Child Development 200273 1220-1237.

26 Angold A, Erkanli A, Silberg J, Eaves L \& Costello EJ. Depression scale scores in 8- to 17-year-olds - effects of age and gender. Journal of Child Psychology and Psychiatry and Allied Disciplines 2002 43 1052-1063.

27 Cairney J \& Wade TJ. The influence of age on gender differences in depression - further population-based evidence on the relationship between menopause and the sex difference in depression. Social Psychiatry and Psychiatric Epidemiology $200237401-408$.

28 Seiffge-Krenke I \& Stemmler M. Factors contributing to gender differences in depressive symptoms: a test of three developmental models. Journal of Youth and Adolescence 200231 405-417.

29 Parker G \& Roy K. Adolescent depression - a review. Australian and New Zealand Journal of Psychiatry 200135 572-580.

30 Buist KL, Dekovic M, Meeus W \& van Aken MAG. Developmental patterns in adolescent attachment to mother, father and sibling. Journal of Youth and Adolescence 200231 167-176.

31 Baumrind D. A developmental perspective on adolescent risktaking in contemporary America. In Adolescent Social Behaviour and Health. Ed. C Irwin. San Francisco: Jossey-Bass, 1987.

32 Spear LP. The adolescent brain and age-related behavioral manifestations. Neuroscience and Biobehavioral Reviews 200024 417-463.

33 Miller-Johnson S, Costanzo PR, Coie JD, Rose MR, Browne DC \& Johnson C. Peer social structure and risk-taking behaviors among African American early adolescents. Journal of Youth and Adolescence 200332 375-384.

34 Brody GH, Ge X, Conger R, Gibbons FX, Murry VM, Gerrard M \& Simons RL. The influence of neighborhood disadvantage, collective 
socialization, and parenting on African American children's affiliation with deviant peers. Child Development 200172 1231-1246.

35 Farrington DP. The development of offending and antisocial behaviour from childhood: key findings from the Cambridge study in delinquent development. Journal of Child Psychology and Psychiatry $1995360929-964$

36 Farrington DP. Age and crime. Crime and Justice - a Review of Research 19867 189-250.

37 Pederson W \& Wichstrom L. Patterns of delinquency in Norwegian adolescents. Journal of British Criminology 199535 543-562.

38 Jessor R. New Perspectives on Adolescent Risk Behvaiour. 1st ed. Cambridge: Cambridge University Press, 1998.

39 Dorn LD, Dahl RE, Williamson DE, Birmaher B, Axelson D, Perel J, Stuhl SD \& Ryan ND. Developmental markers in adolescence. Implications for studies of pubertal processes. Journal of Youth and Adolescence 200332 315-324.

40 Williams JM \& Dunlop LC. Pubertal timing and self-reported delinquency among male adolescents. Journal of Adolescence 199922 157-171.

41 Schuckit M \& Smith T. The relationships of a family history of alcohol dependence, a low level of response to alcohol and six domains of life functioning to the development of alcohol use disorders. Journal of Studies on Alcohol 2000 61 827-835.

42 Hesselbrock M \& Hesselbrock V. Relationship of family history, anti-social personality disorder and personality traits in young men at risk for alcoholism. Journal of Studies on Alcohol 1992 53 619-625.

43 Chassin L, Pitts S, DeLucia C \& Todd M. A longitudinal study of children of alcoholics. Predicting young adult substance use disorders, anxiety, and depression. Journal of Abnormal Psychology 1999108 106-119.

44 Collishaw S, Maughan B, Goodman R \& Pickles A. Time trends in adolescent mental health. Journal of Child Psychology and Psychiatry 200445 (In Press).
45 Flory K, Lynam D, Milich R, Leukefeld C \& Clayton R. Early adolescent through young adult alcohol and marijuana use trajectories. Early predictors, young adult outcomes, and predictive utility. Development and Psychopathology 200416 193-213.

46 Miller B, Norton M, Fan X \& Christopherson C. Pubertal development, parental communication and sexual values in relation to adolescent sexual behaviours. Journal of Early Adolescence 1998 $1827-52$

47 Golding J, Pembrey M \& Jones R. ALSPAC - the Avon Longitudinal Study of Parents and Children. I. Study methodology. Paediatric and Perinatal Epidemiology 200115 74-87.

48 Loeber R, Stouthamer-Loeber M, van Kammen W \& Farrington DIE. Development of a new measure of self-reported anti-social behaviour for young children - prevalence and reliability. In Cross-National Research in Self-Reported Crime and Delinquency, pp 203-225. Ed. M Klein. Kluwer Academic Publishers, 1989.

49 Wolke D, Woods S, Bloomfield L \& Karstadt L. The association between direct and relational bullying and behaviour. Journal of Child Psychology and Psychiatry 2000 41 989-1002.

50 Hansen W, Paskett E \& Carter L. The adolescent sexual activity index (ASAI): a standardised strategy for measuring interpersonal heterosexual behaviours among youth. Health Education Research 199914 485-490.

51 Goodyer I, Wright C \& Altham P. The friendships and recent life events of anxious and depressed school-age-children. British Journal of Psychiatry $1990 \mathbf{1 5 6} 689-698$.

52 Pembrey M \& the ALSPAC Study Team. The Avon Longitudinal Study of Parents and Children (ALSPAC): a resource for genetic epidemiology. European Journal of Endocrinology $2004 \mathbf{1 5 1}$ (Suppl) U125-U129.

Received 26 May 2004

Accepted 5 August 2004 